Brandalise, F.M.P., Valente, C.P., Viana, D.D., and Formoso, C.T. (2018). "Understanding the effectiveness of Visual Management best practices in construction sites" In: Proc. $26^{\text {th }}$ Annual Conference of the International. Group for Lean Construction (IGLC), González, V.A. (ed.), Chennai, India, pp. 754763. DOI: doi.org/10.24928/2018/0452. Available at: www.iglc.net.

\title{
UNDERSTANDING THE EFFECTIVENESS OF VISUAL MANAGEMENT BEST PRACTICES IN CONSTRUCTION SITES
}

\author{
Fernanda M. P. Brandalise ${ }^{1}$, Caroline P. Valente ${ }^{2}$, Daniela D. Viana ${ }^{3}$, \\ and Carlos T. Formoso ${ }^{4}$
}

\begin{abstract}
Visual Management (VM) is a strategy for information management strongly related to one of the core concepts of Lean Production Philosophy, the increase of process transparency. VM is especially important to support continuous improvement and it relies on the effective transmission of information at different hierarchical levels. However, there are some challenges in the implementation of VM in construction: each construction project is unique, site layouts are dynamic environments, and the construction itself might become a visual barrier. This paper aims to analyse the role of a set of VM best practices to support production management, understanding the features that distinguish these practices as advanced ones, i.e. the reasons behind the effectiveness of some VM systems. It is based on two case studies carried out in leading companies in the implementation of Lean Construction in Brazil. Differently from previous studies on $\mathrm{VM}$, this investigation explored the integration of those practices in managerial processes that might use a set of visual devices; whether visual devices are used dynamically in order to support decision-making, especially in collaborative processes. Another contribution of this paper is concerned with classifying VM best practices according to the degree of integration to the managerial routines.
\end{abstract}

\section{KEYWORDS}

Visual Management, Transparency, Lean Construction, Production Planning and Control

$1 \quad$ M.Sc. Student, Building Innovation Research Unit - NORIE, Federal University of Rio Grande do Sul, Brazil, +55 51999302604, fernandampbrandalise@ gmail.com

2 M.Sc., Civil Engineer, Building Innovation Research Unit - NORIE, Federal University of Rio Grande do Sul, Brazil, +61 406671148, carolinevalente@gmail.com

3 Associate Professor, Interdisciplinary Department, Federal University of Rio Grande do Sul, Brazil,danidietz@gmail.com

4 Professor, Building Innovation Research Unit - NORIE, Federal University of Rio Grande do Sul, Brazil,formoso@ufrgs.br 


\section{INTRODUCTION}

Construction sites are usually large and dynamic environments where different crews move around, the layout suffers several modifications throughout the project, and the construction itself might become a visual barrier (Formoso et al. 2002). In comparison to manufacturing, these characteristics represent a major challenge to implement Lean Production Philosophy core principles such as process transparency.

Process transparency makes the main process flows visible and comprehensible from start to finish, through public display of information, organizational and physical means, and measurements (Koskela 2000). It is defined as the ability of a production process (or its parts) to communicate with people (Formoso et al. 2002). Transparency aims to support participatory decision-making, empowering stakeholders with the aim increasing their participation(Greif 1991).

Visual Management (VM) can be defined as a sensory strategy for information management, which is used to increase process transparency (Tezel et al. 2016).If process transparency is successfully implemented, most problems, abnormalities, and waste are easily recognized (Igarashi 1991). VM involvesa set of visual devices that are intentionally designed to enable the sharing of information between people, including messages communicated through any of the five senses (Galsworth 1997). It is a democratic way to extend access to information for a group and not just for an individual (Greif 1991).

Although the core objective of VM is to increase process transparency, it is also related to the reduction of variability (Formoso et al. 2002) and to the implementation continuous improvement (Bernstein 2012), other core Lean Production principles. Besides, VM simplifies production control (Koskela 1992) and allows faster understanding and response to problems(Bateman et al. 2016).

Despite the challenges of implementing VM in construction sites, a large number of VM practices used in manufacturing have been adapted to this industry. In fact, some of VM practices are fairly simple visual devices, such as boards that contain procedure information, production drawings, or performance metrics(Heineck et al. 2002), while other practices are more advanced and require planning and stability within the production system(Tezel et al. 2015).

It is worth considering the idea of implementing practices beyond the idea of routine, as pointed out by Gherardi (2009), i.e. practices can be related to social processes and can be seen as a recurrent pattern of socially sustained action. Therefore, successful implementation of VM practices depends on how people interact with visual devices and how processes are designed or changed due to the support of visual tools. Understanding how a visual practice works require a deep understanding of the context and that is why it is difficult to simply implement a visual practice devised elsewhere, as related social processes are often neglected.

Although several taxonomies have been proposed for VM practices in the literature(Tezel et al. 2016), not much has been discussed on the reasons behind the effectiveness of VM systems. Moreover, the application of VM practices in construction sites at the operational level is still relatively limited. In fact, most visual devices found in 
construction sites are meant to support managerial decisions, usually in the site office, while in working areas mostly health and safety warning boards are found(Tezel et al. 2016), a very basic type of visual tool that is focused on 'information giving' (Galsworth 1997).Moreover, visual devices should not be regarded as an end in itself, but are rather means to improve the performance of production systems(Nicolini 2007).

This paper discusses the role of a set of VM best practices to support production management, emphasizing the features that distinguish these practices as advanced ones. It is based on two case studies, carried out in distinct Brazilian leading companies on the implementation of Lean Construction concepts and tools. The practices selected were explored in terms of their integration with managerial processes that use a set of visual devices and whether these visual devices are used dynamically, i.e. amenable to be changed (rather than static), according to the taxonomy of visual devices suggested by Bititci et al. (2015). They were also analysed according to the ability to support decisionmaking and to encourage collaboration between stakeholders. Another contribution of this paper is concerned with classifying the VM best practices identified according to the degree of integration to the managerial routinesand processes.Similar to the concept of standardised work(Martin and Bell, 2011), VM best practices were defined according to the best current way of VM practice inside the context in which it is used, but always having in mind the need for continuous improvement. As this paper intends to contribute for understanding the reasons behind the effectiveness of VM systems, some ideas could be adopted as a reference for companies that intend to improve and refine their VM systems.

\section{RESEARCH METHOD}

Design Science Research (DSR) was the methodological approach adopted in this investigation. It is a way of producing scientific knowledge that involves the development of an artefact (or a solution concept) to solve classes of problems (Holmström et al. 2009). DSR seems to be an appropriate approach for conducting construction management research, because it promotes the development and implementation of innovative managerial concepts and tools, addressing different practical field problems and providing gains to several stakeholders (Rocha et al., 2012). However, designing useful artefacts is a complex task, as it involves the need for creative advancement in areas where the existing theory is generally insufficient (Hevner et al. 2004).

This research project was divided into three stages. The first stage consisted of an empirical study carried out in construction site of a company in Brazil (named Company A), well known as a leading on the implementation of lean production concepts and practices, such as the visual management system adopted in the site assessed. The empirical study was carried out in a healthcare construction project located in Porto Alegre and an overall assessment of the visual managerial tools that had been implemented in the construction site was conducted in six visits. A protocol for data collection was used to analyse 37 visual devices, including the content, type, and function of information displayed, the target group, the visualization format, the managerial area supported by it, and the static or dynamic format of the visual device. The data were 
organized in a spreadsheet, which made it possible to generate some quantitative results, related to the function performed, as well as information providers and users for the visual devices.

The second stage of the investigation consisted of an empirical study carried out in a company from Fortaleza, Northeast of Brazil (named Company B). This company develops and builds commercial and higher middle-class residential building projects, being also a leading construction company in the implementation of Lean Production concepts and practices in Brazil. This second empirical study was based on data collected in four construction sites: three residential projects and one healthcare and commercial project. The study in Company B was conducted in six visits and had a more descriptive character. It was focused on a small set of practices with the aim of exploring the role of visual devices in managerial routines, especially in terms of supporting coordination and collaboration. A protocol was also devised for data collection and processing, but no quantitative measures were used in this analysis.

Multiple sources of evidence were used in both initial stages: (i) interviews with workers at different hierarchical levels (e.g.: site managers, foreman and labour workers); (ii) direct observation and photography register of the construction site; and (iii) analysis of documents, such as plans, visual schedules, inventory sheets, and standard operating procedures. Also, in Company A, participant observation was made in a planning meeting, and in Company B some data were informally collected in participant observations, as one of the authors worked for a five-year period as an innovation manager in that company.

The third stage consisted of a cross analysis of the data from the two empirical studies, based on a set of VM practices that were considered to be the most advanced ones. The aim of this cross analysis was to understand the reasons behind the effectiveness of VM systems. Moreover, it supported the creation of a taxonomy to classify VM practices according to the degree of integration to the managerial routines and processes.

The following questions were used to guide data collection in the third stage of the research:

- Is the VM practice use integrated with other visual devices?

- Does the VM practice have dynamic characteristics?

- How does the VM practice support decision-making?

- Does the VM practice promote a collaboration?

- What is the degree of integration of the VM practice with managerial routines?

\section{RESEARCH FINDINGS}

\section{Analysis of VM Best Practices}

As described by Valente et al. (2017), based on an overall assessment of 37 visual management devices in Company A,a classification of the visual devices was proposed according to the functions performed and type of information displayed, similar to what Eppler and Burkhard (2007)suggested. It was possible to observe that a large number of 
the visual devices identified in the Company A had basic functions, being used just to identify (30\%), to inform something (25\%) or to assist an activity's execution(17.5\%) in a static way of representation. Few advanced VM practices intending to increase the impact of visual devices in work standards could be observed: only $12.5 \%$ were used to control, $5 \%$ to alert, $5 \%$ to plan and 5\% to guarantee an action by using an error-proof device. In relation to the type of information displayed in visual tools, most aimed to identify or inform, matching the findings of functions performed. Another characteristic observed was the low level of participation of the labour force in conceiving or updating visual devices, resulting in a high workload to some managers, who had to do most of the work related to visual management. One of the recommendations of this study was that Company A should assess the utility of existing visual devices, selecting the most effective ones for supporting decision-making and encouraging reflection and collaboration, offering more support for production planning, control, and improvement (Valente et al. 2017).

Among Company A VM best practices, it is worth emphasizing some. Spray markings were one of the most used visual devices in the construction site. Colour coding was used to point out whether tasks have been approved (green, blue, yellow). An explanatory sheet was available with the meaning of markings (Figure 1). Similar Spray markings were used by the electrical and hydraulic service teams for communication. Symbols were defined according to the type of task to be executed in a particular location. However, no record of these markings is usually made, representing a parallel control in relation to the quality management system.
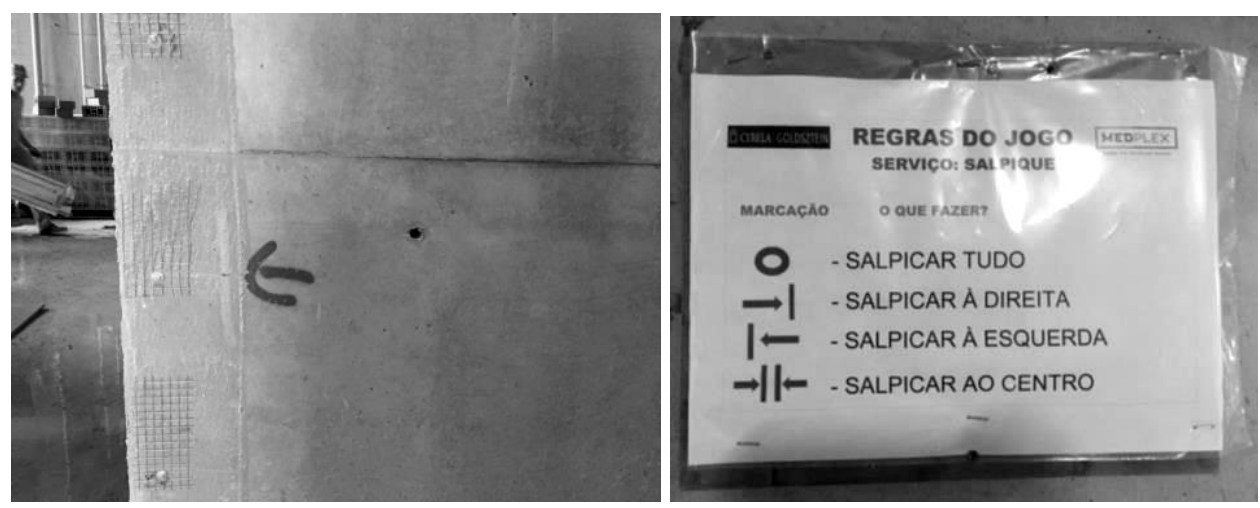

Figure 1: Example of spray marking of the kind of rough cast and it explanatory sheet

It is worth highlighting that some practices are isolated, such as the Spray markings. In other words, these are not well integrated with managerial processes or to other visual devices, and do not support collaborative processes. Despite these limitations, they had a positive impact, as they were dynamic and promoted autonomy among inspectors and the work force, supporting decision-making at the operational level. By contrast, there were practices combining sets of visual devices, which supported collaborative processes, forming what can be named as VM sub-systems. As described by Valente et al. (2017), it is the case of the VM sub-system developed for the installation of drywall partitions, which combined kanban for supplying materials (gypsum and aluminium uprights), 
visual schedule for each floor, standard operating procedure flowchart, material control sheets, physical prototyping, templates, and inspection sheets. This sub-system, in general, presented several good practices, such as dynamic visual tools integrated into the process. Nevertheless, some improvement opportunities were identified in this subsystem, in order to make it more easier to use. As a result, there was a reduction in gypsum plasterboard waste, reduction in the time spent counting components, higher productivity of the material supply teams, better organization of inventories, and increase in the motivation of the employees.

Company B had a larger number of VM practices and sub-systems that can be considered as advanced, i.e. dynamic tools that supported decision-making, being well integrated with managerial routines. These were: Kanban; Andon; Standardised work visual routine cards; Visual board for communal areas; Customization choice board; Visual performance and planning boards; and Physical Prototyping. Those practices and sub-systems were assessed according to the following attributes: the main purpose, people responsible for inputting and updating information, users, and impacts.

For instance, as suggested by Fernandes et al. (2015),Standardised work visual routine cards contains the day, shift, schedule, operation, and production batch for each task, inside the concept of the standardised work. Also, pictograms are sometimes used when employees are illiterate. The innovation manager is the person responsible for creating new cards and updating them, working in close collaboration with operational teams. This kind of device aims to facilitate the understanding of the sequence of operations for employees and supervisors, and due to that, production teams are engaging in the process of continuous improvement. Despite the collaborative creation, Standardised work visual routine cards are a practice and not a sub-system, since its use is not integrated with other visual devices.

Regarding the customization choice board, its content is updated by the customization manager to inform about choices in residential units demanded by the clients, by using a colour scheme (green for the company first choice standard unit, yellow for company's second choice standard or client's purchase, and red for not executing a particular task in the apartment). This device works as a boundary object among different stakeholders, such as the customization manager, site managers, material supply and logistics managers, also clients. By definition, a boundary object transfers and translates information to better collaboration among different stakeholders (Koskela et al. 2016). Therefore, it can be considered a VM sub-system and not only a practice.

Visual performance and planning boards contain the main indicators for each area and also a plan of activities produced by using post-its, containing "to do", "doing" and "done" activities with the purpose of balancing the activities of the team, since each colour represents a team member (Figure 2). They can inform key devices elaborated by other departments of the company, and also indicators, and both look-ahead and weekly work plans, being very flexible to fit information needed by the users. Each department is responsible for its own board and for inputting information to construction site boards, which can be used by several head office departments, as well as by site management. In this specific context, those boards can be considered as VM sub-systems due to the key role in supporting collaboration and the use of a set of integrated visual devices. 


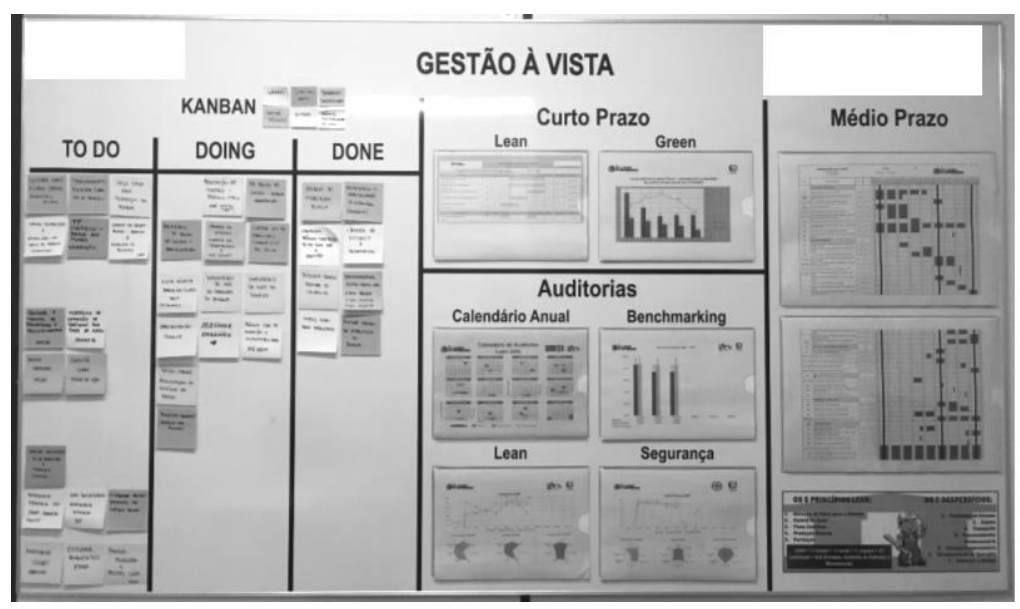

Figure 2: Visual performance and planning boards

\section{DISCUSSION}

A cross analysis was made between the best practices of Company A and Company B, with the aim of understanding the reasons behind the effectiveness of VM systems and why some of them can be considered as advanced. The following criteria were established: (i) whether a practice is integrated or not with other visual devices - this determines if it is only an isolated VM practice or a VM sub-system; (ii) whether a VM practice can be used dynamically (rather than being static); (iii) ability to promote collaborative processes and support decision-making; (iv) whether a VM system promotes autonomy to the workforce; and, finally, the degree of integration with the managerial routines and processes. Based on that criteria, a taxonomy was proposed to classify VM best practices and subsystems. In that taxonomy, the degree of integration to the managerial routines was classified into three main categories: one-to-one, coordination, and collaborative. These three categories are important to understand the role of VM practices in process transparency. Those practices might have different and complementary roles, and do not represent a ranking in terms of significance.

One-to-one category is the most basic form of incorporating visual devices in production processes, in which information must be rapidly and easily understood, being the visual device a clear communication channel between a sender and a receiver. The visual device simply makes public performance measures or instructions to perform a task, using resources such as sound, icons, physical barriers, and color-coding. However, collaboration might not exist in task execution, but only in visual devices' development. The Spray markings of Company A, and Kanban, Andon, and Standardised work cards from Company B fit well this category. Several simple visual devices that work in isolation can also be classified in the One-to-one category, as these do not promote collaborative processes, nor represent a VM sub-system.

The VM sub-system for the installation of drywall partitions from Company A, combining several visual devices, the Visual board for communal areas and the Customization choice board, from Company B, are VM sub-systems that can be included in the Coordination category. These are used to share information and coordinate 
activities between several stakeholders, usually producing routine information. These visual devices are relevant to work routine as they summarize chunks of information in compact formats such as graphs or tables and act as boundary objects.

Finally, the Collaborative category corresponds to the highest level of integration. VM devices enclosed in this category intend to support collaborative processes among different departments or hierarchical levels as well as a specific group of users. They usually are dynamic devices, especially important in environments where innovation and flexibility have a fundamental role, such as the VM sub-system of Visual performance and planning boards of Company B, and others involving cooperative practices such as planning and control, quality assessment, and accident prevention meetings.

Depending on the goal and the way they are used, some VM sub-systems such as Physical Prototyping can be classified into different categories. As exposed by Saffaro et al. (2006) in many companies, this kind of practice does not support any type of collaboration, being considered Coordination category. By contrast, in Company B, Physical Prototyping can be classified in the Collaborative category, as a meeting involving people of many departments (design, sales, and production) is used to share experiences and to define improvement measures.

Figure 3 summarizes the analysis of VM best practices from Company A and Company B.

\begin{tabular}{|c|c|c|c|c|c|c|}
\hline Example & Company & $\begin{array}{c}\text { Integrated use with } \\
\text { other visual device }\end{array}$ & $\begin{array}{c}\text { Dynamic } \\
\text { characteristcs }\end{array}$ & $\begin{array}{c}\text { Support in decison- } \\
\text { making }\end{array}$ & $\begin{array}{c}\text { Promotion of } \\
\text { collaborative process }\end{array}$ & $\begin{array}{c}\text { Degree of integration } \\
\text { with managerial routines }\end{array}$ \\
\hline Spray markings & A & $\begin{array}{c}\text { No } \\
\text { (VM Practice) }\end{array}$ & Yes & Yes & No \\
\hline Kanban & B & $\begin{array}{c}\text { No } \\
\text { (VM Practice) }\end{array}$ & Yes & Yes & No-one \\
\hline Andon & B & $\begin{array}{c}\text { No } \\
\text { (VM Practice) }\end{array}$ & Yes & Yes & No-one \\
\hline $\begin{array}{c}\text { Standardised work visual } \\
\text { routine cards }\end{array}$ & B & $\begin{array}{c}\text { No } \\
\text { (VM Practice) }\end{array}$ & No & Yes & No & One-to-one \\
\hline $\begin{array}{c}\text { Installation of drywall } \\
\text { partitions }\end{array}$ & A & $\begin{array}{c}\text { Yes } \\
\text { (VM Sub-system) }\end{array}$ & Yes & Yes & Yes & Coordination \\
\hline $\begin{array}{c}\text { Visual board for communal } \\
\text { areas }\end{array}$ & B & $\begin{array}{c}\text { Yes } \\
\text { (VM Sub-system) }\end{array}$ & Yes & Yes & Yes \\
\hline $\begin{array}{c}\text { Customization choice board } \\
\text { (VM Sub-system) }\end{array}$ & B & Yes & Yes & Yoordination \\
\hline $\begin{array}{c}\text { Visual performance and } \\
\text { planning boards }\end{array}$ & B & $\begin{array}{c}\text { Yes } \\
\text { (VM Sub-system) }\end{array}$ & Yes & Yes & Yes & Coordination \\
\hline $\begin{array}{c}\text { Physical Prototyping } \\
\text { (VM Sub-system) }\end{array}$ & B & No & Yes & Yes & Collaborative \\
\hline
\end{tabular}

Figure 3: Advanced VM practices and advanced VM sub-systems

\section{CONCLUSION}

The use of Visual Management in construction sites is strongly linked to a set of Lean Philosophy principles, including increase process transparency, variability reduction, and continuous improvement. The more dynamic, collaborative and well-integrated into managerial routines and processes, supporting decision making, the more advanced a VM practice or VM sub-system can be considered, being these the reasons behind the effectiveness of VM systems identified. From a more practical point of view, this paper analysedexamples of some visual practices that support production management and that have been successfully implemented by Lean Construction best-practicing companies 
from Brazil. A taxonomy was proposed to classify them according tothe degree of integration to managerial routines.

Both construction companies had good examples of VM practices and sub-systems, despite the complexity and challenges of this environment. In general, Company B had most advanced VM practices and sub-systems, well integrated into management processes, while in Company A some improvement opportunities were pointed out. Moreover, with the exception of the Standardised work visual routine cards, none of the most advanced practices was developed or implemented with a strong participation of the operational teams at the construction site. This fact points out to the need for greater involvement of the workforce and operational management in Visual Management, which can be initiated through training and collaborative activities. Classifying the advanced VM practices and advanced VM sub-systems into categories, according to the degree of integration to the managerial routines (One-to-one, Coordination, and Collaborative) was a way to better understand the level of collaboration and the effectiveness of VM systems.

Finally, it is worth emphasizing the importance of understanding visual devices as directly and specifically associated with each process context and users in production management. In order to improve continuously VM sub-systems, it is important to address some existing communication problems, the information needs of the target audience, and the way the device can be integrated into the company routine.

\section{REFERENCES}

Bateman, N., Philp, L., and Warrender, H. (2016). "Visual management and shop floor teams - development, implementation and use." International Journal of Production Research, Taylor \& Francis, 54(24), 7345-7358.

Bernstein, E. S. (2012). "The Transparency Paradox: A Role for Privacy in Organizational Learning and Operational Control." Administrative Science Quarterly, Sage Publications, 57(2), 181-216.

Bititci, U., Cocca, P., and Ates, A. (2015). "Impact of visual performance management systems on the performance management practices of organisations." International Journal of Production Research, 7543(October), 1-23.

Eppler, M. J., and Burkhard, R. A. (2007). "Visual representations in knowledge management: framework and cases." Journal of Knowledge Management, 11(4), 112122.

Fernandes, N. B. L. S., Saggin, A. B., Valente, C. P., Brito, F. L., and Mourão, C. A. M. A. (2015). "The Standardized Work Tool Applied To the Waterproofing Process With Acrylic Membrane." Proc. 23rd Ann. Conf. of the Int'l. Group for Lean Construction. Perth, Australia, July 29-31, 133-142.

Formoso, C. T., dos Santos, A., and Powell, J. A. (2002). "An Exploratory Study on the Applicability of Process Transparency in Construction Sites." Journal of Construction Research, 3(1), 35-54.

Galsworth, G. (1997). Visual systems: harnessing the power of the visual workplace. American Management Association, New York.

Gherardi, S. (2009). "Knowing and learning in practice - based studies: an introduction." The Learning Organization, 16(5), 352-359. 
Greif, M. (1991). The visual factory: building participation through shared information. CRC Press, Portland.

Heineck, L. F. M. F. M., Pereira, P. E. E., Leite, M. O. O., Neto, D. P. B. P. B., and Pinho, I. B. B. (2002). "Transparency in building construction: a case study." Proceedings for the 16th Annual Conference of the International Group for Lean Construction, Gramado, Brazil, Brazil, 1-12.

Hevner, A. R., March, S. T., Park, J., and Ram, S. (2004). "Design Science in Information Systems Research.” MIS Quarterly - Research Essay, 28(1), 75-105.

Holmström, J., Ketokivi, M., and Hameri, A.-P. (2009). "Bridging Practice and Theory: A Design Science Approach.” Decision Sciences, 40(1), 65-87.

Igarashi, R. (1991). "The big picture." Visual control systems, E. MCTIGHE, ed., Productivity Press, Cambridge, 3-12.

Koskela, L. (1992). "Application of the new philosophy to construction." Stanford University, Stanford.

Koskela, L. (2000). "An exploration towards a production theory and its application to construction." VTT Building Technology, (L. Ukskoski, ed.), Technical Research Centre of Finland, Espoo, Finland.

Koskela, L., Pikas, E., Gomes, D., Rahim, N., Biotto, C., Talebi, S., Tzortzopoulos, P., Saeed, T., Rahim, N., and Tzortzopoulos, P. (2016). "Towards Shared Understanding on Common Ground, Boundary Objects and Other Related Concepts." 24th Annual Conference of the International Group for Lean Construction, 63-72.

Martin, T., and Bell, J. (2011). New Horizons in Standardized Work - Techniques for Manufacturing and Business Process Improvement.

Nicolini, D. (2007). "Studying visual practices in construction." Building Research \& Information, 35(5), 576-580.

Rocha, C. G. da, Formoso, C. T., Tzortzopoulos, P., Koskela, L., and Tezel, A. (2012). "Design Science Resea Rch in Lean Construction: Proces S and Outcomes."

Saffaro, F. A., Trescastro, M., Rodriguez, A., Schramm, F. K., Formoso, C. T., and Heineck, L. F. (2006). "Prototyping contributions for production management in construction." Proceedings of the 14 th annual conference of the International Group for Lean Construction, 25-27.

Tezel, A., Koskela, L., and Tzortzopoulos, P. (2016). "Visual Management in production management: a literature synthesis." Journal of Manufacturing Technology Management, 27(6), 766-799.

Tezel, A., Koskela, L., Tzortzopoulos, P., Formoso, C. T., and Alves, T. (2015). "Visual Management in Brazilian Construction Companies: Taxonomy and Guidelines for Implementation." Journal of Management in Engineering, 31(6), 1-14.

Valente, C. P., Brandalise, F. M. P., Pivatto, M. P., and Formoso, C. T. (2017). "Guidelines for Devising and Assessing Visual Management Systems in Construction Sites." Proceedings for the 25th Annual Conference of the International Group for Lean Construction (IGLC), 695-702. 